\title{
Lansky Performance Status 40
}

National Cancer Institute

\section{Source}

National Cancer Institute. Lansky Performance Status 40. NCI Thesaurus. Code C70542.

Mostly in bed; participates in quiet activities. 